\title{
Body ownership and embodiment: Vestibular and multisensory mechanisms
}

\section{Mécanismes vestibulaires et multisensoriels dans l'attribution du corps propre et le sentiment d'incarnation}

\author{
C. Lopez, P. Halje, O. Blanke*
}

Laboratory of Cognitive Neuroscience, Brain Mind Institute, école polytechnique fédérale de Lausanne (EPFL), Swiss Federal Institute of Technology, Station 15, 1015 Lausanne, Switzerland

Received 6 June 2007; accepted 31 December 2007

Available online 31 January 2008

\section{KEYWORDS \\ Self-localization; Self-attribution; Corporeal awareness; Neurology; Caloric vestibular stimulations; Vestibular cortex; Weightlessness}

\begin{abstract}
Summary Body ownership and embodiment are two fundamental mechanisms of selfconsciousness. The present article reviews neurological data about paroxysmal illusions during which body ownership and embodiment are affected differentially: autoscopic phenomena (out-of-body experience, heautoscopy, autoscopic hallucination, feeling-of-a-presence) and the room tilt illusion. We suggest that autoscopic phenomena and room tilt illusion are related to different types of failures to integrate body-related information (vestibular, proprioceptive and tactile cues) in addition to a mismatch between vestibular and visual references. In these patients, altered body ownership and embodiment has been shown to occur due to pathological activity at the temporoparietal junction and other vestibular-related areas arguing for a key importance of vestibular processing. We also review the possibilities of manipulating body ownership and embodiment in healthy subjects through exposition to weightlessness as well as caloric and galvanic stimulation of the peripheral vestibular apparatus. In healthy subjects, disturbed self-processing might be related to interference of vestibular stimulation with vestibular cortex leading to disintegration of bodily information and altered body ownership and embodiment. We finally propose a differential contribution of the vestibular cortical areas to the different forms of altered body ownership and embodiment.
\end{abstract}

(c) 2008 Elsevier Masson SAS. All rights reserved.

\footnotetext{
* Corresponding author.

E-mail address: olaf.blanke@epfl.ch (O. Blanke).
} 


\section{MOTS CLÉS}

Localisation de soi ;

Auto-attribution ;

Conscience

corporelle ;

Neurologie ;

Stimulation

vestibulaire

calorique ;

Cortex vestibulaire ;

Microgravité
Résumé L'attribution du corps propre et de ses éléments constitutifs (body ownership), ainsi que le sentiment d'incarnation (embodiment) - le fait d'habiter ce corps, d'être localisé dans les limites physiques de ce corps - , sont deux éléments fondamentaux de la conscience de soi. Nous faisons ici la synthèse de données issues de la neurologie montrant que des manifestations paroxystiques telles que les phénomènes autoscopiques (expérience de sortie du corps, héautoscopie, hallucination autoscopique, sensation de présence) et l'illusion de bascule de l'environnement (room tilt illusion) se caractérisent par une atteinte différentielle des mécanismes d'attribution du corps propre et du sentiment d'incarnation. Nous faisons l'hypothèse que les différents phénomènes autoscopiques et l'illusion de bascule de l'environnement se caractérisent par différents patrons de déficits d'intégration des informations sensorielles corporelles (informations visuelles, musculaires proprioceptives et tactiles) combinés à une perte de cohérence entre les références visuelles et vestibulaires. Chez les patients souffrant de phénomènes autoscopiques, les déficits d'attribution du corps propre et du sentiment d'incarnation ont été liés à un dysfonctionnement au niveau de la jonction temporopariétale et d'autres régions corticales recevant des informations vestibulaires, suggérant une contribution importante des afférences vestibulaires dans les mécanismes de la conscience de soi. Nous rapportons également des données de la littérature recueillies chez des sujets sains suggérant la possibilité de manipuler l'attribution du corps propre et le sentiment d'incarnation par des stimulations artificielles du système vestibulaire périphérique (stimulations vestibulaires caloriques et galvaniques) ou l'apesanteur. Chez des sujets sains, les stimulations vestibulaires, en interférant avec les traitements multisensoriels dans les cortex vestibulaires, conduiraient à une intégration erronée des informations sensorielles corporelles et altéreraient les mécanismes sous-tendant la conscience de soi. Nous proposons finalement une contribution différentielle des aires corticales vestibulaires aux différents troubles de l'attribution du corps propre et du sentiment d'incarnation.

(c) 2008 Elsevier Masson SAS. All rights reserved.

\section{Introduction}

Human bodily experience is characterized by the immediate and continuous experience that our body and its parts belong to us, often called self-attribution, body ownership $[57,74]$ or mineness [91,92]. A related, but distinct, bodily experience is self-localization or embodiment that is defined as the experience that the self is localized at the position of our body at a certain position in space [84]. Recent philosophical and neurological theories converge on the relevance of such bodily experiences and associated processing of bodily information as one promising approach for the development of a comprehensive neurobiological model of self-consciousness $[56,75,92]$. Yet, the scientific investigation of bodily experiences in general, and self-attribution/body ownership and self-localization/embodiment more specifically, have proven difficult and have, in our opinion, not received the attention they deserve given their importance for neuroscientific models of self and self-consciousness [57,91,92].

A few studies have investigated the brain mechanisms involved in the coding of self-attribution for body parts. Data in neurological patients suffering from somatoparaphrenia due to right temporoparietal brain damage show that the self-attribution for a given body part may be seriously disturbed. These patients misattribute one of their hands as belonging to another person or misattribute another person's hand as their own hand $[10,58,102]$. Interestingly, comparable errors in self-attribution have been induced experimentally in healthy subjects during the so-called "rubber hand illusion" by using a fake hand and multisensory conflict [21]. During the rubber hand illusion, erroneous self-attribution of the fake hand is often associated with errors in the localization of one's own hand $[21,114]$. Moreover, neuroimaging studies have revealed that errors in self-attribution and localization of body parts are associated with activation of premotor and posterior parietal cortex [45] as well as posterior insular cortex [115].

Yet, the self is experienced as a single, coherent whole body representation - rather than as multiple representations of separate body parts. Studies on the rubber hand illusion and somatoparaphrenia thus investigated only body part ownership or the attribution and localization of a body part with respect to the global bodily self, that is, a partto-whole relationship. Accordingly, these studies did not investigate global bodily self-consciousness, namely localization and attribution of the entire body or self to which the selected body part is attributed (here called embodiment and body ownership respectively), that has been proposed to be a key phenomenological aspect of self-consciousness [8,56,81,90-92].

In the present article we will review recent data showing that ownership and embodiment can also be disturbed for the entire body. For this, we present four different lines of evidence about ownership and embodiment with respect to the entire body. First, we discuss findings of disturbed body ownership and embodiment in neurological patients suffering from illusory own body perceptions of the entire body called autoscopic phenomena [14,22,28,29,38,69]. Second, mechanisms of disturbed body ownership and embodiment in these patients will be compared with neurological patients suffering from illusory perceptions during which extrapersonal space is experienced as displaced with 


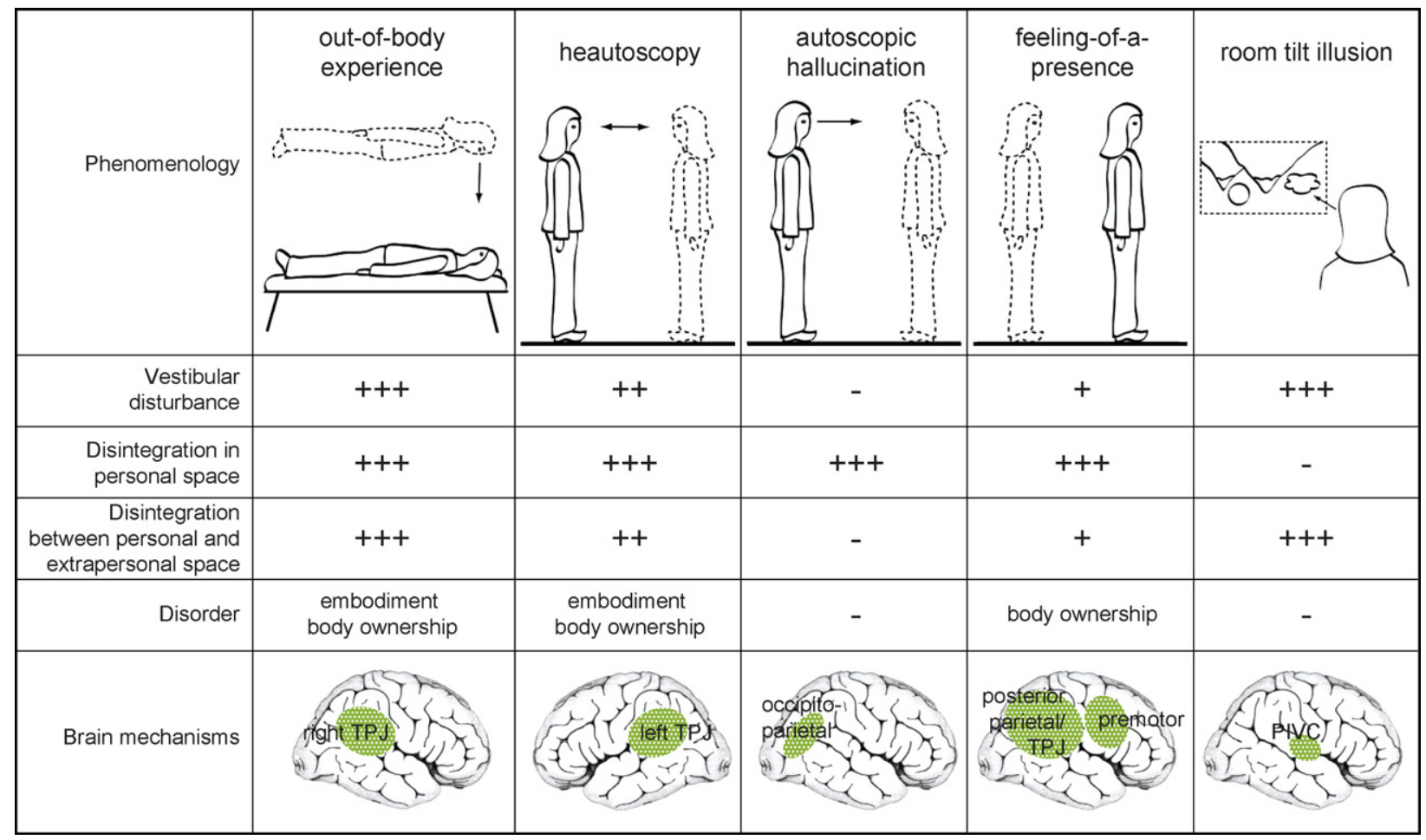

Figure 1 Phenomenology and physiopathology of the autoscopic phenomena and the room tilt illusion. For each paroxysmal illusion, the actual position of the patient's body is schematically represented by black lines and that of the parasomatic body by dashed lines. The direction of the visuospatial perspective is indicated by an arrow pointing away from the location where the patient has the impression he is located. The patient has the impression to see the environment from the physical body in the case of autoscopic hallucination, feeling-of-a-presence and room tilt illusion, alternatively from the physical and the parasomatic body in the case of heautoscopy, and from the parasomatic body in the case of out-of-body experience. The paroxysmal illusions are characterized by a different pattern of vestibular disturbance and of disintegration in personal space and between personal and extrapersonal space. The lower part represents the hypothetical involvement of the different multisensory vestibular regions in the different form of paroxysmal illusion (TPJ: temporoparietal junction; PIVC: parieto-insular vestibular cortex). See text for explanations (drawings by Lovisa Halje after Blanke et al. [14]).

respect to their body (and self), called room tilt illusion $[34,108,113]$. Third, we review conditions of vestibular and multisensory conflicts that are prone to induce body illusions in healthy subjects including astronauts. Fourth, neuroimaging studies mapping the neural structures encoding body ownership and embodiment will be presented. We argue that the elucidation of the neural mechanisms of ownership and embodiment of one's entire body will be of prime importance for the development of neuroscientific models of self-consciousness and subjectivity.

\section{Autoscopic phenomena}

Autoscopic phenomena are illusory own body perceptions that affect the entire body and lead to striking abnormalities in embodiment as well as body ownership. Four types of autoscopic phenomena have been described: autoscopic hallucination, heautoscopy, out-of-body experience, and feeling-of-a-presence (Fig. 1). ${ }^{1}$ They occur after dam-

\footnotetext{
1 Some classifications of autoscopic phenomena include feelingof-a-presence as an autoscopic phenomenon (as it is a reduplication of one's own body $[26,62]$ ), others do not (as it is not a visual
}

age to temporoparietal, frontoparietal or parieto-occipital cortex and are due to distinct patterns of multisensory disintegration of bodily sensory information [12-15]. Autoscopic phenomena strongly suggest that not only self-attribution and localization of body parts, but also of the entire body can be disturbed systematically $[14,28,29]$. In autoscopic hallucinations and heautoscopy patients see a second own (illusory) body in extrapersonal space, but they differ with respect to self-attribution and self-localization with respect to the illusory body. Whereas in autoscopic hallucinations patients do not self-attribute and localize themselves at the position of the illusory body, this is the case in heautoscopy during which patients may experience themselves to be localized at the position of the illusory body, selfattributing the illusory body (see Brugger [28]; Blanke et al. (patient 2 and 4) [14]). Localization and attribution of the self with an illusory body at an extracorporeal position is complete in out-of-body experiences. In this third

reduplication of one's own body as in autoscopic hallucinations, heautoscopy, or out-of-body experiences $[14,15,38])$. Here we discuss feeling-of-a-presence as its pathophysiology is relevant for embodiment and ownership. 
form of autoscopic phenomena patients localise the self outside their body and experience to see their body from this disembodied location. The last form of autoscopic phenomena, feeling-of-a-presence, is not a visual own body illusion, but an illusory own body reduplication during which a second illusory body is felt (but not seen) in extrapersonal space $[4,28,30,31,36,73]$. In feeling-of-a-presence the illusory body is experienced as the body of another human. Embodiment is normal (as in autoscopic hallucinations). Body ownership is disturbed and absent for the illusory second own body. In conclusion, errors in body ownership and embodiment during these four distinct illusory own body perceptions range from absent (autoscopic hallucination) to partial (heautoscopy; feeling-of-a-presence) to fully abnormal (out-of-body experience) ownership and embodiment with another body in a different position in extrapersonal space [12]. We predict that under adequate experimental conditions, it should be possible to manipulate global bodily self-consciousness for the entire body following procedures used in the rubber hand illusion. In fact, recent dat suggest that this is the case [84,44].

The analyses by Blanke et al. [14] and Blanke and Mohr [15] suggest that autoscopic phenomena result from a failure to integrate multisensory bodily information. These authors proposed that autoscopic phenomena result from a disintegration in body or personal space (due to conflicting tactile, proprioceptive, kinesthetic, and visual information) and a second disintegration between personal and extrapersonal space (due to conflicting visual and vestibular information) [see Fig. 1]. While disintegration in personal space was present in all three forms of autoscopic phenomena, differences between the different forms of autoscopic phenomena were mainly due to differences in strength and type of the vestibular dysfunction. Out-of-body experiences were associated with a strong vestibular disturbance, whereas heautoscopy was associated with a moderate and more variable vestibular disturbance, and autoscopic hallucinations without any vestibular disturbance. Moreover, the high frequency of visual hallucinations and hemianopia in patients with autoscopic hallucinations suggested that deficient visual processing of bodily information is the main causing factor for disintegration in personal space in autoscopic hallucinations. These data suggest that heautoscopy is primarily due to abnormal somatosensory (or sensorimotor) information processing, whereas out-of-body experiences are due to abnormal vestibular information processing (for further details see [15]). For the feeling-ofa-presence, it has been proposed that mainly sensorimotor processes are disturbed [4]. With respect to body ownership, these data suggest collectively that somatosensory and vestibular signals are of key importance (abnormal body ownership in out-of-body experiences, heautoscopy and feeling-of-a-presence), whereas visual mechanisms are less important (normal body ownership in autoscopic hallucinations). Vestibular mechanisms seem to be most important in coding embodiment (see Lopez and Blanke [86]).

With respect to involved brain regions, early studies implicated posterior brain regions including the temporal, parietal, or occipital lobe [28,38]. More recently, Blanke and colleagues [11,13-15,17,33] showed that out-of-body experiences and heautoscopy are primarily associated with damage or electrical stimulation at the temporoparietal junction (TPJ) and autoscopic hallucinations with damage in parieto-occipital cortex. This has been confirmed by Maillard et al. [88] and Brandt et al. [23] and in a recent study of 37 neurological cases with out-of-body experiences, heautoscopy, or autoscopic hallucinations due to focal brain damage that have been reported in the medical literature since 1923 [15]. Moreover, these lesion data suggest that out-of-body experiences are associated with damage to the right TPJ [15], heautoscopy with damage to the left TPJ [15], autoscopic hallucinations with damage to the right parieto-occipital cortex [13], and feeling-of-apresence with damage to right and left frontoparietal cortex [31].

It has been suggested that all autoscopic phenomena that lead to disturbances in ownership and embodiment are due to disturbed multisensory bodily integration at the TPJ, but interfere with distinct mechanisms leading to distinct disturbances in embodiment and body ownership. Embodiment and body ownership are disturbed in heautoscopy and out-of-body experiences due to impaired vestibular and somatosensory (proprioceptive) information processing. In autoscopic hallucinations, both impairments are absent or milder. These data suggest that the brain mechanisms of embodiment and body ownership are linked. Yet, the data on the feeling-of-a-presence suggest that in some instances embodiment and body ownership can be dissociated as the feeling-of-a-presence is characterized by disturbed body ownership (or self-attribution of the illusory body) but normal embodiment. In this condition disturbed body ownership has been linked to abnormal sensorimotor processing (rather than disturbed vestibular and proprioceptive processing). Collectively, these data suggest that vestibular and somatosensory multisensory processing, as well as sensorimotor processing are important mechanisms in coding for embodiment and body ownership. In the next section we will review data on a neurological condition that is characterized by a failure to encode the position of one's body in extrapersonal space: the room tilt illusion.

\section{Room tilt illusion}

The room tilt illusion is a paroxysmal and transient tilt of the entire visual surrounding without mislocalization of one's own body $[25,108,113]$. Typically, subjects report a sudden upside-down reversal ( $180^{\circ}$ inversion of the visual field) or a $90^{\circ}$ tilt of the extrapersonal world with respect to their body (Fig. 1, right part). The room tilt illusion may last from several seconds to hours. In most cases, inversion or tilt occurs in the frontal plane, but both have also been described in the horizontal and sagittal planes [108,113]. Room tilt illusion has been associated with lesion of the brainstem and vestibulocerebellar system $[34,41,71,103,109,111,113]$, lesions of the parieto-occipital and frontal cortex (see review in [108]), peripheral vestibular disorders [89], and it has even been described in healthy subjects $[89,101]$.

Room tilt illusion and out-of-body experience share several characteristics suggesting they are subtended by closely related mechanisms [14]. First, both phenomena are mostly paroxysmal and the illusory perception can revert to a normal state spontaneously or after brief eye closure. Second, both phenomena are associated with deficits or disintegra- 
tion of vestibular otolithic cues. Out-of-body experiences are associated with feelings of elevation and floating [14] and room tilt illusion can be evoked by otolithic stimulation [113] and often occurs while subjects are driving or moving [89], or in microgravity [79]. Third, for both illusions, there is a disintegration between personal and extrapersonal space, resulting in a $180^{\circ}$ inversion between the observer and extrapersonal space. Nevertheless, whereas during the room tilt illusion, it is the extrapersonal space, which seems inverted or tilted with respect to a stable observer, it is the body and the visuospatial perspective of the observer, which seem inverted in out-of-body experiences. Another fundamental difference between both illusions is that in the case of the room tilt illusion there is no disintegration of multisensory bodily information from personal space. Furthermore, the room tilt illusion is not (or has not been described to be) associated with deficits in embodiment and body ownership as is strongly the case in out-of-body experiences. $^{2}$ Collectively, these observations suggest that the room tilt illusion is likely a transient mismatch between the visual and vestibular 3D coordinate maps at the cortical level (see [24]), and that an additional cortical disintegration of body-related information (in personal space) seems necessary to induce an out-of-body experience as well as other autoscopic phenomena.

\section{Manipulating body ownership and embodiment in healthy subjects}

Given the above links between body ownership and embodiment with disturbed vestibular cortical processing it is conceivable that interference with peripheral vestibular signals might lead to disturbed body ownership, embodiment, and other own-body cognitions with relevance for the neurobiology of self-consciousness. We will highlight several situations that are characterized by disturbed vestibular information processing such as weightlessness and different kinds of natural and artificial vestibular stimulations that are likely to disturb body ownership and embodiment.

\section{Effects of the gravitational environment on body ownership and embodiment}

Our bodies have evolved in earth gravity and have consequently adapted to a constant linear acceleration of $9.8 \mathrm{~m} / \mathrm{sec}^{2}$. Reports from subjects experiencing microgravity show that the absence of this acceleration can trigger a number of illusory own body perceptions. This indicates that not only the anatomy of the body is predisposed for living in gravity; perceptual functions such as body perception and space perception also seem to have internalized earth gravity in a fundamental way [35,93].

In the presence of gravity, weightlessness can only be obtained by free fall and is thus normally experienced only for brief moments. Prolonged free fall is usually created by flying an aircraft in a parabola, or flying a spacecraft

\footnotetext{
2 Subjects with room tilt illusions do not seem to report disembodiment, yet we were not able to evaluate whether this has been asked for explicitly.
}

in orbit around the earth. In parabolic flight, the free fall lasts for about $30 \mathrm{sec}$, while in orbital flight one can keep on falling for several months. The data obtained from orbital and parabolic flights both show that subjects have a vivid sensation of bodily and extrapersonal up and down in microgravity, regardless of their theoretical understanding that up and down are "meaningless" concepts in such conditions. Accordingly, a range of visual and bodily illusions have been reported, and it is reasonable to assume that these illusions are a result of lacking gravitational signals, multisensory disintegration, and top-down influences. Generally, the percept of verticality only disappears in complete deprivation of vestibular, somatosensory and visual cues, i.e. when people are free-floating with closed eyes [79]. Such a state is often described as being disoriented or having a lack of spatial anchoring. It is not clear whether "a lack of spatial anchoring"' simply refers to the sensation of finding oneself in an unexpected position when opening one's eyes, or if it refers rather to a sensation of the self-existing without space and embodiment. In a study on Russian cosmonauts [78], 98\% of the cosmonauts experienced disorientation during free-floating with closed eyes. However, none of these cosmonauts reported spontaneously about having alterations in their sense of body ownership or embodiment.

The most common own body illusion in microgravity is the inversion illusion $[68,78,79]$, first described by Graybiel and Kellogg [59]. It is defined as a feeling of the body and/or the room (room tilt illusion) being upside-down relative to extrapersonal space. The inversion illusion is frequently reported in parabolic flights and was observed by Lackner [79] in 66 of 68 subjects while subjects were strapped in a chair. According to this author, multiple combinations of room tilt illusion and inversion illusion occur. This indicates that there is a dissociation between brain mechanisms for personal orientation and extrapersonal orientation in space: (i) the person feels like he/she is upside-down while the room is in its canonical orientation (e.g. the floor of the aircraft is interpreted as being down); (ii) the person feels upright while the room is upside-down; (iii) the person feels upside-down in an upside-down room. Case (i) and (ii) are geometrically paradoxical, and in these cases many subjects report that their visual scene appears as being reversed (e.g. objects to their right are seen to their left) or dissociated (e.g. objects in the center of the visual field are appearing in their correct position while surrounding objects are inverted). In parabolic flight, these illusions can be so compelling that the subjects assume an incorrect position when they are preparing themselves for the end of the parabola. Subjects reported that touch and pressure cues had a strong influence on the inversion illusion, which shows that in the absence of otholithic cues, the perception of verticality and up-down orientation become heavily dependent on somatosensory input. For instance, Gazenko (1964) reported that cosmonauts could control their inversion illusion by straining their muscles and thereby gaining a foothold on their chair. In some subjects, the inversion illusion is showing signs of a disintegration between self and body coordinates [79]. These subjects report that their body is being transformed in a "telescopic" fashion into the inverted position, which could be a way of reconstructing the experience of having the sense of verticality being flipped while at the same time the body remains strapped to a chair. This sug- 
gests a potential link between the inversion illusion and the out-of-body experience, since both illusions involve an inversion of the sense of up and down. However, the latter comes with the feeling of disembodiment in addition.

Beside the inversion illusion, a wide range of states with illusory self-location have been described in microgravity. Kornilova [77] makes a distinction between illusory body movement "kinetic illusions" and illusory body position, body configuration, and body verticality "coordinate illusions". Kinetic illusions of rotation occur in the sagittal, frontal or transverse plane, with the sagittal plane being the most common plane of rotation. Kinetic illusions of translation are reported both along the longitudinal body axis (sometimes accompanied by a sensation of falling/rising) and in the left-right direction. Beside the inversion illusion, the illusions of being in a tilted position (with reference to some imagined vertical) are the most frequent coordinate illusions. The tilts are experienced in the sagittal or the frontal plane, with backward tilts being more common than forward tilts, and right tilts being more common than left tilts. All illusions described above involve disturbed selflocation but there are no indications of overt disembodiment or alterations in body ownership that have been mentioned in these reports. Purely visual illusions without illusory selflocation are also common and characterized by surrounding objects or the whole visual scene that are perceived as moving, rotating or displaced.

We conclude that illusory percepts regarding both the own body and the extrapersonal space are common in microgravity. Abnormal vestibular information leads to errors in body localization, body acceleration and body configuration, but these conditions are not associated with abnormal self-attribution and full-blown disembodiment.

\section{Effects of natural and artificial vestibular stimulations on body ownership and embodiment}

Natural vestibular stimulations (by modification of the subject's own body position with respect to gravity) and artificial stimulations of the peripheral vestibular apparatus (by caloric or galvanic vestibular stimulation) are also effective experimental manipulations for investigating the influence of vestibular cues on the mechanisms of body ownership and embodiment.

The fact that out-of-body experiences are more frequent in the supine position suggests that there is a gravitational influence on embodiment and body ownership. On the basis of an analysis in 176 healthy subjects, Green [60] reported that about $73 \%$ of out-of-body experiences occurred when subjects were lying down (e.g. "I was lying on my back when I realized that I was hovering over the bed, looking down on myself''). Similarly more than $80 \%$ of the neurological patients with out-of-body experiences were in supine position [15]. A recent neuroimaging study in healthy subjects showed that neural mechanisms of embodiment in TPJ and occipitotemporal cortex are significantly affected by subject's body position with respect to gravity [5]. This was found especially when imagined self-location was congruent with the subject's physical body position. In addition, the authors described an activation in lateral occipitotemporal cortex that was stronger in the sitting than supine position corresponding with the extrastriate body area [42] and lesion location in patients with autoscopic hallucinations [15]. These data further point to interactions between embodiment, vestibular processing, and autoscopic phenomena at the TPJ and in the occipitotemporal cortex (Fig. 2).

In order to investigate the influence of vestibular signals on embodiment and body ownership, artificial stimulations of the peripheral vestibular systems have been carried out using caloric and galvanic vestibular stimulation (see [86] for an overview). Galvanic vestibular stimulation has been shown to induce strong disturbances in self-location, by creating illusory own body perceptions characterized by an apparent tilt towards the cathode with respect to the gravitational vertical (for recent overviews see [52,83]). As this illusory own body perception was observed while the subject's head was fixed, there is a clear dissociation between the perceived body position (self-location) and the physical body position (body location) that remained vertically oriented. Accordingly, we propose that this spatial dissociation between self and body location (that is very prominent in out-of-body experiences) might reflect partial disembodiment as it can be observed in patients with autoscopic phenomena in whom vestibular illusions are often associated symptoms $[14,17,83]$ and in healthy subjects using multisensory conflict and virtual reality [84]. This observation is supported by the activation of the vestibular cortex by galvanic vestibular stimulations $[6,32,37,46,51,85,110]$ overlapping with key structures of embodiment such as the TPJ and the temporooccipital cortex $[5,16]$.

Further findings suggest that abnormal vestibular information influences embodiment and body ownership. Yen Pik Sang et al. [120] reported that caloric vestibular stimulations in healthy subjects may induce transient symptoms of depersonalization and derealisation ("body feels strange/different in some ways", "feeling of detachment or separation from surroundings') by a disintegration in personal space and/or disintegration between personal and extrapersonal space. In a PET study on depersonalization, Simeon et al. [106] found brain activation changes related to embodiment in regions that have also been shown to be activated by caloric vestibular stimulation, such as the superior temporal gyrus, posterior insula and inferior parietal lobule $[19,20,39,47,50,112]$. Collectively, these findings suggest that caloric vestibular stimulation interferes with self-processing and embodiment, also inducing symptoms of depersonalization, which share several aspects with out-ofbody experiences [105].

In addition, caloric vestibular stimulation interferes with illusory own body perceptions of body parts. Thus, caloric vestibular stimulation modifies the experience of phantom limb sensations in paraplegic [80] and amputated [2] patients. These authors were able to evoke transient perceptions of phantom limbs in patients who did previously not experience such sensations suggesting a direct influence of vestibular processing on body part illusions. Observations in brain-damaged patients also found an effect of vestibular stimulation on mechanisms of body part ownership. There are several reports showing that caloric vestibular stimulation may affect somatosensory processing in the case of personal neglect (see [116] for an overview). Bisiach et al. [10] described a patient with somatoparaphrenia, (a neu- 
(A)<smiles>c1cncc(-c2ccco2)c1</smiles>
Mirror task (MIR)

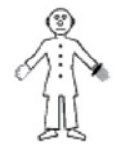

right

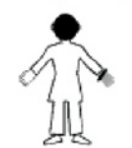

right

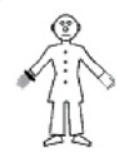

left

Own-body transformation (OBT)<smiles>c1ccc(-c2ccco2)cc1</smiles>

left

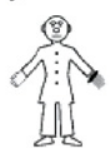

left

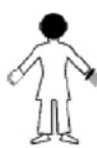

right

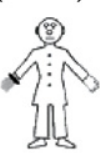

right

(C)

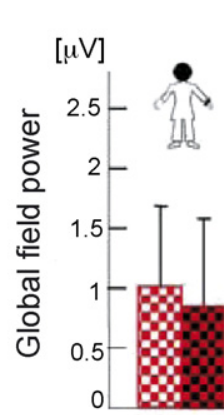

Sitting

Supine

(B)

Sitting position
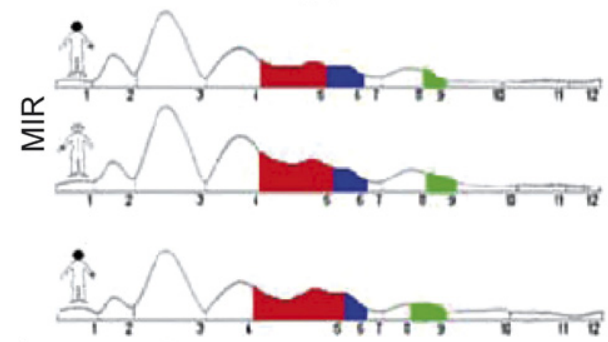

คั

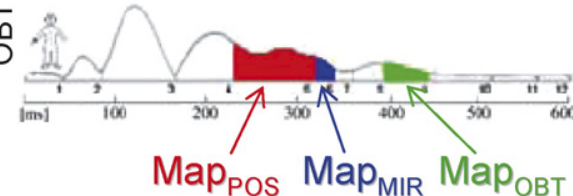

(D)

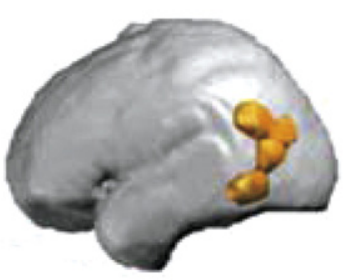

Generators of Map pos

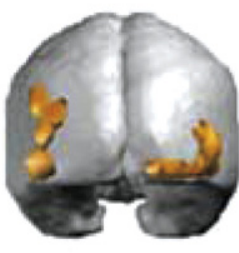

品
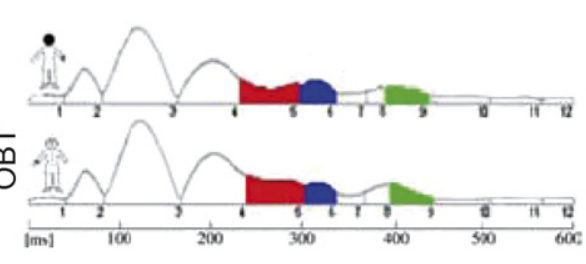

Supine position

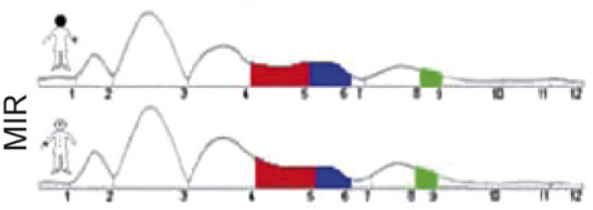

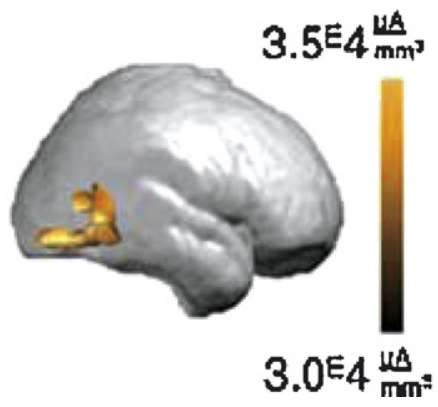

Figure 2 Body position influences the neural basis of embodiment. (A) Stimuli for the mental-imagery tasks. Representation of the four stimuli used for the mirror task (MIR) and the own-body transformation task (OBT). In the MIR task, subjects had to imagine that the human figure was their mirror reflection and to judge which hand was marked in grey. In the OBT task subjects had to do the same judgment but had to imagine themselves in the position of the human figure. The correct answers are indicated under each stimulus. Note that in the MIR task, subjects imagined themselves at their physical body position (embodied self-location) whereas in the OBT task they imagined themselves at an extracorporeal position (disembodied self-location); (B) Event related potential data during the MIR and the OBT tasks for supine and upright subjects. The curves represent the global field power from 0 to $600 \mathrm{~ms}$ poststimulation with the 12 segments of stable map topography in the different experimental conditions (front- and back-facing human figures, MIR and OBT tasks, sitting and supine position). Segment 6 (MAP $\sim 285$ to $330 \mathrm{~ms}$ and was longer for the MIR task than the OBT task in the sitting position. Segment 9 (MAP was found from $\sim 350$ to $400 \mathrm{~ms}$ and was longer for the OBT task than the MIR task in the sitting and supine positions. Segment 5 (MAPpos, in red) was found from $\sim 230$ to $310 \mathrm{~ms}$; (C): Mean global field power of MAPpos. The amplitude of the global field power of $M A P_{\text {POS }}$ was higher for the sitting than the supine position in the MIR and OBT tasks; (D) Localization of the generators of MAP POs. A linear inverse solution localized the generators of MAP pos bilaterally in the lateral occipitotemporal cortex corresponding with the extrastriate body area. Adapted from Arzy et al. [5] with permission of the authors. 
rological condition in which the patient misidentified her left arm as belonging to her mother), whose abnormal left arm ownership was normalized by vestibular caloric stimulation. Collectively, these observations suggest that body cognition as well as body ownership and embodiment may be manipulated by artificial vestibular stimulation.

\section{The vestibular cortex: a multisensory network coding for body ownership and embodiment?}

The reviewed evidence of disturbed body ownership and embodiment from autoscopic phenomena and room-tilt illusion in neurological patients as well as the effects of microgravity and vestibular stimulations in healthy subjects points to a key role of vestibular and multisensory processing in coding body ownership and embodiment. In this final section, we attempt to provide a neuroanatomical framework for the brain mechanisms of body ownership and embodiment giving special reference to vestibular and multisensory cortices.

\section{The vestibular cortex}

Several areas that receive vestibular cues have been described in non-human primate cortex and human cortex (for reviews see $[9,25,54,67,87,97])$. Electrophysiological recordings in macaque, squirrel and marmoset monkeys showed that many neurons are driven by vestibular inputs in a region that Grüsser and colleagues called "parieto-insular vestibular cortex" (PIVC) $[61,63-65,67]$. Anatomically, this region is located in the depth of the Sylvian fissure at the level of the posterior insula extending posteriorly to the retroinsular cortex as well as anteriorly to the parietal operculum. The PIVC is considered to be the core region of the vestibular cortex because it is strongly connected or interconnected with most of the other vestibular cortical areas [67]. There is evidence that the TPJ/insula represents the human homologue of the monkey PIVC although its exact location in the human brain is still debated. In presurgical epilepsy patients, Penfield [98] reported that electrical stimulation of the superior temporal gyrus evokes vestibular illusions like "dizziness, swinging, spinning" (case \#94), "sinking feeling"' (case \#5), or that the "head rest seems to be jumping up and down"' (case \#25). This was confirmed more recently by Kahane et al. [76] who showed that electrical stimulation applied in different loci of the superior and middle temporal gyri elicited similar illusions such as e.g. "levitation, lightness" (case \#9712b), "rolling forwards" (case \#9712c) and "head spinning"' (case \#9701) [Fig. 3A]. Congruently, epileptic patients with vestibular aurae suffer from lesions surrounding the superior temporal gyrus and the temporoparietal cortex $[99,107]$. This location has also been confirmed by functional neuroimaging studies in healthy subjects using caloric and galvanic stimulation of the peripheral vestibular system revealing unanimously predominant activations centered on the TPJ and insula $[6,19,20,32,39,46,47,50,51,70,72,85,94,95,110,112,118]$ with activations in the superior temporal gyrus, posterior insula, inferior parietal lobule (angular and supramarginal gyri), and postcentral gyrus. Although many regions surrounding the TPJ/insula have been found activated, opinions concerning the exact location of the human homologue of the PIVC differ (Fig. 3) [see Fig. 3B].

Although the PIVC is the core region of the vestibular cortex, several other areas encode vestibular information including somatosensory cortex (areas 3av and 2v), superior parietal cortex (area 7), as well as premotor (area 6) and cingulate cortices, and hippocampus (Fig. 3B). In somatosensory cortex vestibular stimulations activate the anterior tip of the intraparietal sulcus $[50,85,94,112]$ and the primary somatosensory cortex, near the central sulcus $[20,47,50,100]$. These regions represent probably the human homologue of two monkey areas that have been found to integrate vestibular and somatosensory information: area $2 v$, at the base of the intraparietal sulcus [53] and area 3av at the hand/arm and neck/trunk representations $[66,96]$. Another vestibular area has been described in the posterior parietal cortex and was activated during caloric and galvanic vestibular stimulations particularly in the intraparietal sulcus $[50,85,112]$ and superior parietal lobule [118]. These regions are likely homologous to monkey area 7 [82] and the ventral and medial intraparietal areas $[27,77]$ receiving vestibular information as well as visual, somatosensory and auditory cues. There is finally evidence of vestibular projections to the primary motor and premotor cortices (including also the frontal eye fields), and to the inferior frontal gyrus, in relation to the vestibular control of motor and oculomotor functions $[6,47,50,85,94]$.

\section{Linking abnormal body ownership and embodiment at the multisensory vestibular cortex}

Electrophysiological $[67]$ and neuroimaging $[6,19,40]$ studies showed that the vestibular cortex is a multisensory cortex receiving not only vestibular information, but also visual cues (especially optokinetic cues: PIVC, area $2 v$, ventral intraparietal area), proprioceptive cues from the neck and lower limb muscles, as well as tactile cues from the plantar surface of the feet (areas 2v, 3av, PIVC). We believe that these multisensory interactions are fundamental for integrating signals about body movement and body position in space (on the basis of vestibular, proprioceptive and visual cues), head and body position with respect to other body segments (on the basis of proprioceptive and visual cues) and body contact with respect to the ground (through tactile cues). Only under conditions of congruent multisensory integration in this multisensory vestibular network an accurate representation of body location in space as well as selflocation generated. Based on the reviewed evidence, we have proposed above (Section 2) that the different forms of illusory own body perceptions that are associated with abnormal embodiment and body ownership are due to different abnormalities in multisensory integration of bodily information in vestibular and multisensory cortices $[12,14]$. Here we will extend this model by proposing a differential implication of different cortical structures of the multisensory vestibular network in generating the different forms of illusory own body perceptions (see Fig. 1, lower part).

We hypothesize a double disintegration of visual and vestibular cues (disintegration between extrapersonal and personal space) on one hand, and of visual, tactile and proprioceptive cues (disintegration in personal space) on 
(A)

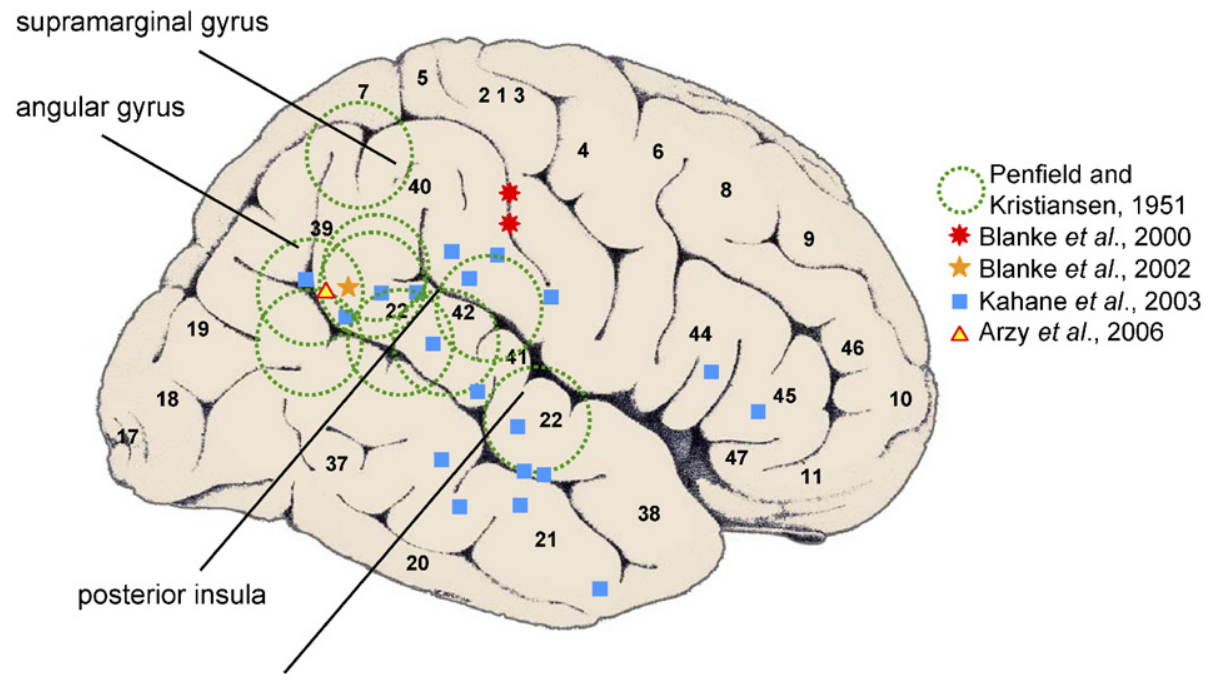

superior temporal gyrus

(B) posterior parietal cortex somatosensory cortex

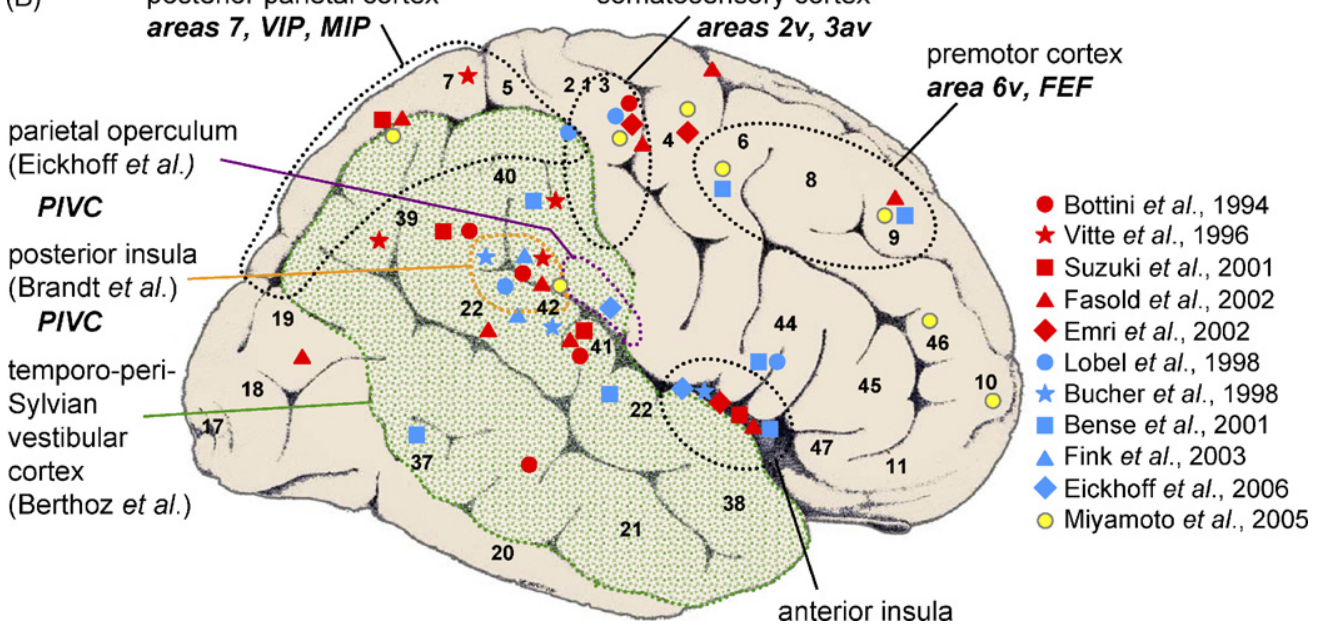

Figure 3 The human vestibular cortex. (A) Vestibular areas evidenced in epileptic patients. The green dotted circles represent the localization of epileptogenic lesions responsible for vestibular illusions. Filled symbols represent the site at which focal electrical stimulation evoked vestibular illusions (Blanke et al. [17,18]; Kahane et al. [75]) and the illusory feeling-of-a-presence behind the patient's body (Arzy et al. [4]); (B) Vestibular areas evidenced in healthy subjects. Vestibular-receiving areas demonstrated by neuroimaging studies during caloric (red symbols) and galvanic (blue symbols) stimulations of the peripheral vestibular apparatus as well as during $102 \mathrm{~dB}$ auditory clicks (yellow symbols). To summarize, right and left cerebral activations are reported on a lateral view of the right hemisphere (modified after [43]). The monkey vestibular areas are indicated in bold letters: PIVC (parieto-insular vestibular cortex), VIP (ventral intraparietal area), MIP (medial intraparietal area), FEF (frontal eye fields) and areas $2 \mathrm{v}, 3 \mathrm{av}, 6 \mathrm{v}$ and 7. The human homologue of the PIVC has been localized at least at three different locations. Brandt and colleagues suggested that the posterior insula represents the human PIVC [25] since lesions centered on the posterior insula impaired the perception of the visual vertical and induced rotational vertigo and unsteady gait (orange dotted circle). Berthoz and colleagues suggested that the homologue of PIVC is rather at the level of the temporoparietal junction including more anterior parts of the superior temporal gyrus and not necessarily involving the insula [75,84], naming this region rather the "temporo-peri-Sylvian vestibular cortex"' (green dotted area). Recent data comparing the anatomical localization of the vestibular cortex as defined by fMRI with cytoarchitectonic mapping suggest that the human analogue of the PIVC is localized in the parietal operculum [45] (purple dotted circle).

the other hand, that occur in out-of-body experience and heautoscopy to be due to abnormal activity in the human PIVC/TPJ. A key contribution of the PIVC is suggested since single neurons in this region integrate vestibular, visual, and somatosensory cues $[61,65]$. In support of this view, patients presenting out-of-body experiences and heautoscopy have lesions centered on the TPJ including the angular gyrus and the superior temporal gyrus $[14,15]$. The implication of the TPJ in embodiment is suggested by neuroimaging studies in healthy subjects showing its key role in computing the egocentric reference frame $[19,55,117]$ and in mental imagery/transformation involving one's own-body $[16,104,121]$ as well as employing embodied and disembodied self-location [5]. Furthermore, damage of the TPJ and insula would also account for the disturbances in body ownership reported during out-of-body experience and 
heautoscopy. In support of this view, a recent fMRI study showed that the posterior insula is a key area for coding ownership for one's hands [115]. The TPJ/insula has also been involved in the self-attribution of seen movements and agency [48,49] and first-person-perspective taking [119]. We wonder why there is a different involvement of right and left TPJ in autoscopic phenomena as there is evidence that out-of-body experiences are more frequent after damage to the right TPJ causing stronger and distinct abnormalities in body ownership and embodiment than heautoscopy. This seems to be in agreement with the general observation that corporeal awareness and the experience of body ownership are more likely dependent on the right hemisphere $[1,7]$. In healthy subjects, sense of body ownership and self-attribution of actions are also more specifically related to right posterior insula activity $[49,115]$. Also, there is an overall right hemispheric dominance for the vestibular cortex $[39,46,50,51,112]$, and the integration of vestibular and proprioceptive cues seems to involve particularly the right TPJ (see Bottini et al. [19]). In the case of autoscopic hallucinations, lesion sites are mostly located in right parieto-occipital and temporo-occipital cortex with less involvement of the TPJ $[13,15]$. This is in line with the more frequent visual hallucinations and less frequent vestibular illusions encountered in autoscopic hallucination than in out-of-body experience and heautoscopy. Accordingly, we hypothesize that autoscopic hallucinations may involve posterior parts of the vestibular cortex like area 7 (see patient 5 in [14]). Because, during the feeling-ofa-presence, the illusory body is felt but not seen and the position of the illusory body often mimics the patients' posture, we have speculated that sensorimotor processing is disturbed, possibly at the TPJ and/or parietal and premotor regions of the vestibular network $[4,12]$. The implication of the TPJ and frontoparietal cortex is supported by frequent sensorimotor hemisyndromes in patients suffering from feeling-of-a-presence as compared to patients complaining from out-of-body experience. The feeling-ofa-presence is often confined to one side of the patient's body, contralaterally to the brain lesion, and can appear in combination with spatial neglect $[30,31]$. In line with these arguments, Brugger et al. [31] reported that eight out of 12 patients suffering from feeling-of-a-presence due to brain damage have lesions involving the parietal cortex (cases 2, 8, 9, 11, 12, 16 and 18), and Arzy et al. [4] were able to evoke feeling-of-a-presence during electrical stimulation of the left TPJ. Abnormal vestibular processing in the TPJ and/or parietal cortex is probably present as well since patients suffering from feeling-of-a presence may have a history of vertigo (see cases 2, 3 and 4 [31]). A contribution of the frontoparietal cortex is further supported by clinical [3] and neuroimaging data [45] showing the key contribution of the premotor cortex in body ownership.

As during the room tilt illusion there is a failure to integrate visual extrapersonal and otolithic vestibular cues, this illusion has been assumed to be caused by interference with the PIVC, where gravitational pathways have been found to terminate [25,26]. However, a contribution of the parieto-occipital and frontal cortex has also been suggested [108]. We assume the implication of the PIVC in the room tilt illusion to be distinct from its implication in out-ofbody experiences and heautoscopy as during the room tilt illusion there is only abnormal processing with respect to body location in extrapersonal space without pathologies of embodiment and body ownership. This seems related to the absence of disintegration in personal space during the room tilt illusion. Thus, a single disintegration in personal space (autoscopic hallucination) or in extrapersonal space (room tilt illusion) does seem necessary, but not sufficient to induce disorders of embodiment and ownership that only occurs in states of double disintegration. Room tilt illusion as compared to out-of-body experience and heautoscopy may thus have partly overlapping neural mechanisms, but also distinct neural substrates at the TPJ.

\section{Conclusion}

In conclusion, two important bodily experiences - namely embodiment and body ownership - have been reviewed as they seem to be of key importance for bodily selfconsciousness. Both global bodily experiences are disturbed in neurological patients experiencing autoscopic phenomena and in healthy subjects in whom integration of multisensory and vestibular bodily information is experimentally disturbed. Embodiment is disturbed in patients with outof-body experiences and heautoscopy, but not in patients with autoscopic hallucinations, feeling-of-a-presence and patients with the room tilt illusion. Body ownership is disturbed in patients with out-of-body experiences, heautoscopy and feeling-of-a-presence but never in patients with autoscopic hallucinations, room tilt illusions, and inversion illusions. We propose that these different illusions are related to different patterns of pathological multisensory activity in the cortical vestibular network. Particularly, the most dramatic form of autoscopic phenomena, the outof-body experience, is tightly associated with vestibular sensations and damage to the core region of the vestibular cortex, the PIVC. Accordingly, we believe that performing caloric and galvanic vestibular stimulations in healthy subjects will be an efficient way to disturb the integration of multisensory bodily information and investigate the neural basis of ownership and embodiment. We are optimistic that such an approach will contribute to the development of a fascinating aim of cognitive neuroscience, namely to provide a neuroscientific theory of self, self-consciousness, and subjectivity.

\section{Acknowledgements}

The authors are supported by the Fondation de famille Sandoz, the Cogito Foundation, the Fondation Odier and the Swiss National Science Foundation (SNF grant number 3100A0-112493).

\section{References}

[1] Aglioti S, Smania N, Manfredi M, Berlucchi G. Disownership of left hand and objects related to it in a patient with right brain damage. Neuroreport 1996;8(1):293-6.

[2] André JM, Martinet N, Paysant J, Beis JM, Le Chapelain L. Temporary phantom limbs evoked by vestibular caloric stimulation in amputees. Neuropsychiatry Neuropsychol Behav Neurol 2001;14(3):190-6. 
[3] Arzy S, Overney LS, Landis T, Blanke O. Neural mechanisms of embodiment: asomatognosia due to premotor cortex damage. Arch Neurol 2006;63(7):1022-5.

[4] Arzy S, Seeck M, Ortigue S, Spinelli L, Blanke O. Induction of an illusory shadow person. Nature 2006;443(7109):287.

[5] Arzy S, Thut G, Mohr C, Michel CM, Blanke O. Neural basis of embodiment: distinct contributions of temporoparietal junction and extrastriate body area. J Neurosci 2006;26(31):8074-81.

[6] Bense S, Stephan T, Yousry TA, Brandt T, Dieterich $M$. Multisensory cortical signal increases and decreases during vestibular galvanic stimulation (fMRI). J Neurophysiol 2001;85(2):886-99.

[7] Berlucchi G, Aglioti S. The body in the brain: neural bases of corporeal awareness. Trends Neurosci 1997;20(12):560-4.

[8] Bermudez JL. The paradox of self-consciousness. Cambridge, MA: The MIT Press; 1998.

[9] Berthoz A. How does the cerebral cortex process and utilize vestibular signals? In: Baloh RW, Halmagyi GM, editors. Disorders of the vestibular system. New York: Oxford University Press; 1996. p. 113-25.

[10] Bisiach E, Rusconi ML, Vallar G. Remission of somatoparaphrenic delusion through vestibular stimulation. Neuropsychologia 1991;29(10):1029-31.

[11] Blanke O, Arzy S. The out-of-body experience: disturbed selfprocessing at the temporo-parietal junction. Neuroscientist 2005;11(1):16-24.

[12] Blanke O, Arzy S, Landis T. Illusory perceptions of the human body and self. In: Goldenberg G, Miller B, editors. Handbook of Clinical Neurology. Neuropsychology and behavioral neurology, Vol 88. Paris: Elsevier; 2008.

[13] Blanke O, Castillo V. Clinical neuroimaging in epileptic patients with autoscopic hallucinations and out-of-body experiences. Epileptologie 2007;24:90-6.

[14] Blanke O, Landis T, Spinelli L, Seeck M. Out-of-body experience and autoscopy of neurological origin. Brain 2004;127(Pt 2):243-58.

[15] Blanke O, Mohr C. Out-of-body experience, heautoscopy, and autoscopic hallucination of neurological origin. Implications for neurocognitive mechanisms of corporeal awareness and self-consciousness. Brain Res Brain Res Rev 2005;50(1):184-99.

[16] Blanke O, Mohr C, Michel CM, Pascual-Leone A, Brugger P, Seeck $M$, et al. Linking out-of-body experience and self processing to mental own-body imagery at the temporoparietal junction. J Neurosci 2005;25(3):550-7.

[17] Blanke O, Ortigue S, Landis T, Seeck M. Stimulating illusory own-body perceptions. Nature 2002;419(6904):269-70.

[18] Blanke O, Perrig S, Thut G, Landis T, Seeck M. Simple and complex vestibular responses induced by electrical cortical stimulation of the parietal cortex in humans. J Neurol Neurosurg Psychiatry 2000;69(4):553-6.

[19] Bottini G, Karnath HO, Vallar G, Sterzi R, Frith CD, Frackowiak RS, et al. Cerebral representations for egocentric space: functional-anatomical evidence from caloric vestibular stimulation and neck vibration. Brain 2001;124(Pt 6): 1182-96.

[20] Bottini G, Sterzi R, Paulesu E, Vallar G, Cappa SF, Erminio F, et al. Identification of the central vestibular projections in man: a positron emission tomography activation study. Exp Brain Res 1994;99(1):164-9.

[21] Botvinick M, Cohen J. Rubber hands "feel" touch that eyes see. Nature 1998;391(6669):756.

[22] Bradford DT. Autoscopic hallucinations and disordered selfembodiment. Acta Neuropsychol 2005;3(3):120-89.

[23] Brandt C, Brechtelsbauer D, Bien CG, Reiners K. Out-of-body experience as possible seizure symptom in a patient with a right parietal lesion. Nervenarzt 2005;76(10):1259, 61-2.
[24] Brandt T. Cortical matching of visual and vestibular 3D coordinate maps. Ann Neurol 1997;42(6):983-4.

[25] Brandt T, Dieterich $M$. The vestibular cortex. Its locations, functions, and disorders. Ann N Y Acad Sci 1999;871:293-312.

[26] Brandt T, Dieterich $M$. Vestibular syndromes in the roll plane: topographic diagnosis from brainstem to cortex. Ann Neurol 1994;36(3):337-47.

[27] Bremmer F, Schlack A, Duhamel JR, Graf W, Fink GR. Space coding in primate posterior parietal cortex. Neuroimage 2001;14(1 Pt 2):S46-51.

[28] Brugger P. Illusory reduplication of one's own body: phenomenology and classification of autoscopic phenomena. Cogn Neuropsychiatr 1997;2(1):19-38.

[29] Brugger P. Reflective mirrors: perspective-taking in autoscopic phenomena. Cogn Neuropsychiatry 2002;7(3):179-94.

[30] Brugger P. Are "presences" preferentially felt along the left side of one's body? Percept Mot Skills 1994;79:1200-2.

[31] Brugger P, Regard M, Landis T. Unilaterally felt "presences"': the neuropsychiatry of one's invisible Doppelgänger. Neuropsychiatry Neuropsychol Behav Neurol 1996;9(2): 114-22.

[32] Bucher SF, Dieterich $M$, Wiesmann $M$, Weiss A, Zink $R$, Yousry TA, et al. Cerebral functional magnetic resonance imaging of vestibular, auditory, and nociceptive areas during galvanic stimulation. Ann Neurol 1998;44(1):120-5.

[33] Bunning S, Blanke 0 . The out-of body experience: precipitating factors and neural correlates. Prog Brain Res 2005; 150:331-50.

[34] Charles N, Froment C, Rode G, Vighetto A, Turjman F, Trillet M, et al. Vertigo and upside down vision due to an infarct in the territory of the medial branch of the posterior inferior cerebellar artery caused by dissection of a vertebral artery. J Neurol Neurosurg Psychiatry 1992;55(3):188-9.

[35] Clément G, Moore ST, Raphan T, Cohen B. Perception of tilt (somatogravic illusion) in response to sustained linear acceleration during space flight. Exp. Brain Res 2001;138(4):410-8.

[36] Critchley M. The idea of a presence. Acta Psychiatr Neurol Scand 1955;30(1-2):155-68.

[37] Deutschländer A, Bense S, Stephan T, Schwaiger M, Brandt T, Dieterich $M$. Sensory system interactions during simultaneous vestibular and visual stimulation in PET. Hum Brain Mapp 2002;16(2):92-103.

[38] Devinsky O, Feldmann E, Burrowes K, Bromfield E. Autoscopic phenomena with seizures. Arch Neurol 1989;46(10):1080-8.

[39] Dieterich $M$, Bense S, Lutz S, Drzezga A, Stephan T, Bartenstein $P$, et al. Dominance for vestibular cortical function in the non-dominant hemisphere. Cereb Cortex 2003;13(9):994-1007.

[40] Dieterich M, Bucher SF, Seelos KC, Brandt T. Horizontal or vertical optokinetic stimulation activates visual motionsensitive, ocular motor and vestibular cortex areas with right hemispheric dominance. An fMRI study. Brain 1998;121(Pt 8):1479-95.

[41] Dogulu CF, Kansu T. Upside-down reversal of vision in multiple sclerosis. J Neurol 1997;244(7):461.

[42] Downing PE, Jiang Y, Shuman M, Kanwisher N. A cortical area selective for visual processing of the human body. Science 2001;293(5539):2470-3.

[43] Duvernoy HM. The human brain. Surface, blood supply, and three-dimensional sectional anatomy. 2nd ed. Wien: SpringerVerlag; 1999, 491.

[44] Ehrsson HH. The experimental induction of out-of-body experiences. Science 2004;317(5641): 1048.

[45] Ehrsson HH, Spence C, Passingham RE. That's my hand! Activity in premotor cortex reflects feeling of ownership of a limb. Science 2004;305(5685):875-7.

[46] Eickhoff SB, Weiss PH, Amunts K, Fink GR, Zilles K. Identifying human parieto-insular vestibular cortex using 
fMRI and cytoarchitectonic mapping. Hum Brain Mapp 2006;27(7):611-21.

[47] Emri M, Kisely M, Lengyel Z, Balkay L, Marian T, Miko L, et al. Cortical projection of peripheral vestibular signaling. J Neurophysiol 2003;89(5):2639-46.

[48] Farrer C, Franck N, Frith CD, Decety J, Georgieff N, d'Amato T, et al. Neural correlates of action attribution in schizophrenia. Psychiatry Res 2004;131(1):31-44.

[49] Farrer C, Franck N, Georgieff N, Frith CD, Decety J, Jeannerod M. Modulating the experience of agency: a positron emission tomography study. Neuroimage 2003;18(2):324-33.

[50] Fasold O, von Brevern M, Kuhberg M, Ploner CJ, Villringer A, Lempert $\mathrm{T}$, et al. Human vestibular cortex as identified with caloric stimulation in functional magnetic resonance imaging. Neuroimage 2002;17(3):1384-93.

[51] Fink GR, Marshall JC, Weiss PH, Stephan T, Grefkes C, Shah NJ, et al. Performing allocentric visuospatial judgments with induced distortion of the egocentric reference frame: an fMRI study with clinical implications. Neuroimage 2003;20(3):1505-17.

[52] Fitzpatrick RC, Day BL. Probing the human vestibular system with galvanic stimulation. J Appl Physiol 2004;96(6): 2301-16.

[53] Fredrickson JM, Figge U, Scheid P, Kornhuber HH. Vestibular nerve projection to the cerebral cortex of the rhesus monkey. Exp Brain Res 1966;2:318-27.

[54] Fukushima K. Corticovestibular interactions: anatomy, electrophysiology, and functional considerations. Exp Brain Res 1997;117(1):1-16.

[55] Galati G, Committeri G, Sanes JN, Pizzamiglio L. Spatial coding of visual and somatic sensory information in body-centred coordinates. Eur J Neurosci 2001;14(4):737-46.

[56] Gallagher S. How the body shapes the mind. Owford: Oxford University Press; 2005.

[57] Gallagher S. Philosophical conceptions of the self: implications for cognitive science. Trends Cogn Sci 2000;4(1): 14-21.

[58] Gerstmann J. Problem of imperception of disease and of impaired body territories with organic lesions. Relations to body scheme and its disorders. Arch Neurol Psychiatr 1942;48:890-913.

[59] Graybiel A, Kellogg RS. Inversion illusion in parabolic flight: its probable dependence on otolith function. Aerosp Med 1967;38(11):1099-103.

[60] Green CE. Out-of-body experiences. Oxford: Institute of Psychophysical Research; 1968.

[61] Grüsser OJ, Guldin WO, Mirring S, Salah-Eldin A. Comparative physiological and anatomical studies of the primate vestibular cortex. In: Albowitz B, Albus K, Kuhnt U, Nothdurf HC, Wahle $P$, editors. Structural and functional organization of the neocortex. Berlin: Springer-Verlag; 1994. p. 358-71.

[62] Grüsser OJ, Landis T. The splitting of "l"' and "me"': heautoscopy and related phenomena. In: Grüsser OJ, Landis T, editors. Visual agnosias and other disturbances of visual perception and cognition. Amsterdam: MacMillian; 1991. p. 297-303.

[63] Grüsser OJ, Pause M, Schreiter U. Localization and responses of neurones in the parieto-insular vestibular cortex of awake monkeys (Macaca fascicularis). J Physiol 1990;430(1):537-57.

[64] Grüsser OJ, Pause M, Schreiter U. Neural responses in the parieto-insular vestibular cortex of alert Java Monkey (Macaca fascicularis). In: Roucoux A, Crommelinck M, editors. Physiological and pathological aspects of eye movements. The Hague, Boston, London: Jung; 1982. p. 251-70.

[65] Grüsser OJ, Pause M, Schreiter U. Vestibular neurones in the parieto-insular cortex of monkeys (Macaca fascicularis): visual and neck receptor responses. J Physiol 1990;430(1):559-83.
[66] Guldin WO, Akbarian S, Grüsser OJ. Cortico-cortical connections and cytoarchitectonics of the primate vestibular cortex: a study in squirrel monkeys (Saimiri sciureus). J Comp Neurol 1992;326(3):375-401.

[67] Guldin WO, Grüsser OJ. Is there a vestibular cortex? Trends Neurosci 1998;21(6):254-9.

[68] Gurovskiy NN, Bryanov II, Yegorov AD. Changes in the vestibular function during space flight. Acta Astronaut 1975;2(3-4):207-16.

[69] Hécaen H, Ajuriaguerra J. Méconnaissances et hallucinations corporelles. Paris: Masson; 1952.

[70] Hegemann S, Pawlowski M, Huonker R, Haueisen J, Fitzek C, Fetter M. Magnetoencephalography during optokinetic and vestibular activation of the posterior insula. Ann $\mathrm{N}$ Y Acad Sci 2003;1004:457-64.

[71] Hernandez AH, Pujadas F, Purroy F, Delgado P, Huertas R, Alvarez-Sabin J. Upside down reversal of vision due to an isolated acute cerebellar ischemic infarction. J Neurol 2006;253(7):953-4.

[72] Indovina I, Maffei V, Bosco G, Zago M, Macaluso E, Lacquaniti F. Representation of visual gravitational motion in the human vestibular cortex. Science 2005;308(5720):416-9.

[73] Jasper K. Über leibhafte Bewusstheiten (Bewusstheitstäuschungen), ein psychopathologisches Elementarsymptom. Z Pathopsychol 1913;2:150-61.

[74] Jeannerod $M$. The mechanism of self-recognition in humans. Behav Brain Res 2003;142(1-2):1-15.

[75] Jeannerod $M$. The origin of voluntary action: history of a physiological concept. C R Biol 2006;329(5-6):354-62.

[76] Kahane P, Hoffmann D, Minotti L, Berthoz A. Reappraisal of the human vestibular cortex by cortical electrical stimulation study. Ann Neurol 2003;54(5):615-24.

[77] Klam F, Graf W. Vestibular response kinematics in posterior parietal cortex neurons of macaque monkeys. Eur J Neurosci 2003;18(4):995-1010.

[78] Kornilova LN. Orientation illusions in spaceflight. J Vestib Res 1997;7(6):429-39.

[79] Lackner JR. Spatial orientation in weightless environments. Perception 1992;21(6):803-12.

[80] Le Chapelain L, Beis JM, Paysant J, André JM. Vestibular caloric stimulation evokes phantom limb illusions in patients with paraplegia. Spinal Cord 2001;39(2):85-7.

[81] Legrand D. Pre-reflexive self-consciousness: on being bodily in the world. Janus Head 2007;9(2):493-519.

[82] Leinonen L, Hyvarinen J, Sovijarvi AR. Functional properties of neurons in the temporo-parietal association cortex of awake monkey. Exp Brain Res 1980;39(2):203-15.

[83] Lenggenhager B, Smith ST, Blanke O. Functional and neural mechanisms of embodiment: importance of the vestibular system and the temporal parietal junction. Rev Neurosci 2006;17(6):643-57.

[84] Lenggenhager B, Tadi T, Metzinger T, Blanke O. Video ergo sum: manipulating bodily self-consciousness. Science 2007;317(5841):1096-9.

[85] Lobel E, Kleine JF, Le Bihan D, Leroy-Willig A, Berthoz A. Functional MRI of galvanic vestibular stimulation. J Neurophysiol 1998;80(5):2699-709.

[86] Lopez C, Blanke O. Neuropsychology and neurophysiology of self-consciousness. Multisensory and vestibular mechanisms. In: Holderegger A, Sitter-Liver B, Hess CW, Rager G, editors. Hirnforschung und Menschenbild. Beiträge zur interdisziplinären Verständigung. Fribourg and Schwabe, Basel: Academic Press; 2007. p. 183-206.

[87] Lopez C, Lacour M, Borel L. Perception de la verticalité et représentations spatiales dans les aires corticales vestibulaires. In: Lacour $M$, Weber $B$, editors. Bipédie, contrôle postural et représentation corticale. Marseille: Solal; 2005. p. $35-86$. 
[88] Maillard L, Vignal JP, Anxionnat R, TaillandierVespignani L. Semiologic value of ictal autoscopy. Epilepsia 2004;45(4):391-4.

[89] Malis DD, Guyot JP. Room tilt illusion as a manifestation of peripheral vestibular disorders. Ann Otol Rhinol Laryngol 2003;112(7):600-5.

[90] Merleau-Ponty M. Phenomenology of perception (Smith, C. Transl. 1962. London: Routledge); 1945.

[91] Metzinger T. Being No One, 3. Cambridge: MIT Press; 2003.

[92] Metzinger T. Empirical perspectives from the self-model theory of subjectivity: a brief summary with examples. Prog Brain Res 2007;168:215-78.

[93] Mittelstaedt $\mathrm{H}$. A new solution to the problem of the subjective vertical. Naturwissenschaften 1983;70(6):272-81.

[94] Miyamoto T, Fukushima K, Takada T, de Waele C, Vidal PP. Saccular projections in the human cerebral cortex. Ann N Y Acad Sci 2005;1039:124-31.

[95] Naito Y, Tateya I, Hirano S, Inoue M, Funabiki K, Toyoda H, et al. Cortical correlates of vestibulo-ocular reflex modulation: a PET study. Brain 2003;126(Pt 7):1562-78.

[96] Ödkvist LM, Schwarz DWF, Fredrickson JM, Hassler R. Projection of the vestibular nerve to the area $3 a$ arm field in the squirrel monkey (Saimiri sciureus). Exp Brain Res 1974;21:97-105.

[97] Paulesu E, Frackowiak RS, Bottini G. Maps of somatosensory systems. In: Frackowiak RS, Friston KJ, Frith CD, Dolan RJ, Mazziotta JC, editors. Human brain function. San Diego: Academic Press; 1997. p. 183-242.

[98] Penfield W. Vestibular sensation and the cerebral cortex. Ann Otol Rhinol Laryngol 1957;66:691-8.

[99] Penfield W, Kristiansen K. Epileptic seizure patterns, ed. Thomas CC. 1951, Springfield, Ilinois. 48-50.

[100] Petit L, Beauchamp MS. Neural basis of visually guided head movements studied with fMRI. J Neurophysiol 2003;89(5):2516-27.

[101] Querner V, Schenk T, Brandt T. Motion-induced transient room tilt illusion in an otherwise healthy subject. Neuroophtalmology 1999;22(3):169-76.

[102] Rode G, Charles N, Perenin MT, Vighetto A, Trillet M, Aimard G. Partial remission of hemiplegia and somatoparaphrenia through vestibular stimulation in a case of unilateral neglect. Cortex 1992;28(2):203-8.

[103] Ropper AH. Illusion of tilting of the visual environment. Report of five cases. J Clin Neuroophthalmol 1983;3(2):147-51.

[104] Ruby P, Decety J. Effect of subjective perspective taking during simulation of action: a PET investigation of agency. Nat Neurosci 2001;4(5):546-50.

[105] Simeon D, Gross S, Guralnik O, Stein DJ, Schmeidler J, Hollander E. Feeling unreal:30 cases of DSM-III-R depersonalization disorder. Am J Psychiatry 1997;154(8):1107-13.
[106] Simeon D, Guralnik O, Hazlett EA, Spiegel-Cohen J, Hollander E, Buchsbaum MS. Feeling unreal: a PET study of depersonalization disorder. Am J Psychiatry 2000;157(11):1782-8.

[107] Smith BH. Vestibular disturbances in epilepsy. Neurology 1960;10:465-9.

[108] Solms M, Kaplan-Solms K, Saling M, Miller P. Inverted vision after frontal lobe disease. Cortex 1988;24(4):499-509.

[109] Steiner I, Shahin R, Melamed E. Acute "upside down"' reversal of vision in transient vertebrobasilar ischemia. Neurology 1987;37(10):1685-6.

[110] Stephan T, Deutschländer A, Nolte A, Schneider E, Wiesmann $M$, Brandt $T$, et al. Functional MRI of galvanic vestibular stimulation with alternating currents at different frequencies. Neuroimage 2005;26(3):721-32.

[111] Stracciari A, Guarino M, Ciucci G, Pazzaglia P. Acute upside down reversal of vision in vertebrobasilar ischaemia. J Neurol Neurosurg Psychiatry 1993;56(4):423.

[112] Suzuki M, Kitano H, Ito R, Kitanishi T, Yazawa Y, Ogawa T, et al. Cortical and subcortical vestibular response to caloric stimulation detected by functional magnetic resonance imaging. Brain Res Cogn Brain Res 2001;12(3):441-9.

[113] Tiliket C, Ventre-Dominey J, Vighetto A, Grochowicki M. Room tilt illusion. A central otolith dysfunction. Arch Neurol 1996;53(12):1259-64.

[114] Tsakiris $M$, Haggard P. The rubber hand illusion revisited: a visuotactile integration and self-attribution. J Exp Psychol Hum Percept Perform 2005;31(1):80-91.

[115] Tsakiris M, Hesse MD, Boy C, Haggard P, Fink GR. Neural Signatures of Body Ownership: A Sensory Network for Bodily Self-Consciousness. Cereb Cortex 2006.

[116] Vallar G. Spatial hemineglect in humans. Trends Cog Neurosci 1998;2(3):87-97.

[117] Vallar G, Lobel E, Galati G, Berthoz A, Pizzamiglio L, Le Bihan D. A fronto-parietal system for computing the egocentric spatial frame of reference in humans. Exp Brain Res 1999;124(3):281-6.

[118] Vitte E, Derosier C, Caritu Y, Berthoz A, Hasboun D, Soulie D. Activation of the hippocampal formation by vestibular stimulation: a functional magnetic resonance imaging study. Exp Brain Res 1996;112(3):523-6.

[119] Vogeley K, Fink GR. Neural correlates of the first-personperspective. Trends Cogn Sci 2003;7(1):38-42.

[120] Yen Pik Sang F, Jauregui-Renaud K, Green DA, Bronstein AM, Gresty MA. Depersonalisation/derealisation symptoms in vestibular disease. J Neurol Neurosurg Psychiatry 2006;77(6):760-6.

[121] Zacks JM, Ollinger JM, Sheridan MA, Tversky B. A parametric study of mental spatial transformations of bodies. Neuroimage 2002;16(4):857-72. 